\title{
ONION-LIKE OFF-FLAVOUR IN BEER: ISOLATION AND IDENTIFICATION OF THE CULPRITS
}

\author{
by \\ ARNE OLSEN, \\ Department of Brewing Chemistry, Carlsberg Research Center, \\ Gamle Carlsberg Vej 10, DK-2500 Copenhagen Valby \\ BO WERNER CHRISTENSEN and JØRGEN ØGAARD MADSEN \\ Department of Organic Chemistry, \\ The Technical University of Denmark, DK-2800 Lyngby
}

Keywords: Beer, sulphur compounds, (1-methylethyl)-thiirane, 2-mercapto-3-methyl-1-butanol, off-flavour, onion, extraction, gas chromatography, mass spectrometry, taste testing

Beer with an onion-like off-flavour is found to contain two unusual sulphur compounds: (1-methylethyl)-thiirane and 2-mercapto-3-methyl-1-butanol. The off-flavour is attributable to the latter, previously unknown compound. The methods used are: extraction of beer with trichlorofluoromethane, $\mathrm{GC}$ analyses of extractives and reference compounds, using a sulphur sensitive flame photometric detector, and GC-MS. Both of the new sulphur constituents are synthesized and their structures ascertained by NMR and MS.

\section{INTRODUCTION}

The flavour of beer comprises a vast number of constituents. The great majority of these are present in amounts below their individual organoleptical threshold-values for detection (10). Off-flavour in beer is conceived as an undesirable, often unpleasant, deviation from the flavour of beer of usual quality. Off-flavours may arise from normal flavour constituents present in enhanced concentrations, or from one or more compounds not normally occurring in beer.

Certain sulphur compounds are known to cause disagreeable off-flavours, even in very low concentrations. A well-known example is the "light-struck" flavour in beer that has been exposed to sunlight, caused by 3-methyl-2buten-1-thiol, arising from photolysis of hop iso- $\alpha$-acids $(4,8)$ which mainly are isohumulone, isocohumulone, and isoadhumulone (6). Another off-flavour, perceived as "onion-like", has been occasionally noticed by taste testing panels at the breweries. Onion-like off-flavours have been repeatedly referred to in the brewery literature. Thus in an investigation of Finnish beer a special flavour note was characterized as onion-like (cooked onion) (7), whereas another Finnish paper (1) reported that trub sedimenta-

Abbreviations: FID = flame ionization detector; FPD = flame photometric detector; GC = gas chromatography; MS = mass spectrometry; NMR = nuclear magnetic resonance; TMS = tetramethylsilane. 
tion in wort at 40 and $60{ }^{\circ} \mathrm{C}$ in pilot plant experiments in certain cases resulted in beer with an onion smell. This was believed to result from a change in yeast metabolism induced by a nutritional deficiency (1). Hot aeration of brewer's wort has been discussed as a cause of onion smell of the beer obtained $(2,9)$ as has the mechanical action of centrifugal pumps and high pressure homogenisers on the wort (11). The onion-like off-flavour encountered by the taste testing panels is believed to be the same as that caused by mechanical action on wort (11), whereas it remains uncertain to what extent the other onion-like off-flavours mentioned above are identical or similar to each other and to ours. Specific compounds responsible for the onion smell have not been identified in the cases cited. In the literature some compounds have been suggested as responsible for the onion-or garliclike off-flavour in beer, e.g. diethyl disulphide (10) and dimethyl trisulphide $(13,15)$. When added to beer, these compounds, however, produced flavour notes that were different from the off-flavour studied here, but the disappearance of the latter after addition of cupric sulphate to the beer does suggest that one or more sulphur compounds are involved. Since identification of the compound(s) responsible for the off-flavour might conceivably help clarifying the circumstances relevant to its appearance, we have undertaken a study of its chemical nature. The present paper describes our methods and results.

\section{MATERIAIS AND METHODS}

\subsection{Beer samples and solvent}

Samples of beer with onion-like off-flavour were obtained from selected batches brewed in the pilot plant brewery at Carlsberg Research Center. Carlsberg lager beer was used as reference. The extraction solvent, trichlorofluoromethane (Frigen 11) was purchased from Hoechst.

\subsection{Extraction of beer and concentration of extracts \\ 2.2.1. Small-scale, single-step extraction}

Beer, $280 \mathrm{ml}$, in a bottle, was cooled on ice, vigorously shaken with $2 \mathrm{ml}$ of trichlorofluoromethane for $2 \mathrm{~min}$, and left on ice for $30 \mathrm{~min}$. Most of the beer was decanted off and the bottom layer isolated with a cooled pipette. Small amounts of beer were separated from the extract by short centrifuging. Approximately 1 $\mathrm{ml}$ of extract was collected in a small glass vial and concentrated in an ice bath with a stream of $\mathrm{N}_{2}$ gas to a final volume of 4-5 $\mu$ l.

\subsubsection{Continuous extraction}

In a standard glass apparatus for the continuous extraction of a liquid with a heavier liquid was placed $35 \mathrm{ml}$ of trichlorotrifluoromethane and, with slow pouring, $670 \mathrm{ml}$ of beer; most of the beer foam was sucked away. The boiling flask was loaded with $50 \mathrm{ml}$ of the solvent. The extraction was run for $3.5 \mathrm{~h}$ with a solvent flux of about $2 \mathrm{l} / \mathrm{h}$. The condenser was cooled with ice and only minute amounts of solvent (b.p. 24 ${ }^{\circ} \mathrm{C}$ ) were lost. The drops of solvent coming from the condenser must be large, using a wide-bore guide tube; otherwise an emulsion layer will build up and eventually pass over into the boiling flask. Approximately $45 \mathrm{ml}$ of extract solution was obtained. Portions of this, 10-15 $\mathrm{ml}$, were concentrated to a volume of $100 \mu \mathrm{l}$ by distilling off solvent through a short Vigreux column.

\subsection{Gas chromatography}

Packed column GC was carried out on a Perkin-Elmer Sigma 3B instrument equipped with a flame ionization detector (FID), using either a $1.5 \mathrm{~m} \times 2 \mathrm{~mm}$ (i.d.) glass column packed with 5\% OV-101 on Chromosorb W HP, 80/100 mesh or a $2.4 \mathrm{~m} \times 3 \mathrm{~mm}$ (i.d.) glass column packed with $6.6 \%$ Carbowax $20 \mathrm{M}$ on Chromosorb W HP, 80/100 mesh. The latter column, used for preparative work and for olfactory analyses of beer extracts, protruded into the injection port (standard glass liner removed) to allow on-column injection. With the aid of a splitter (T-piece and glass-lined 1/16" steel tubings) located in the oven the eluate was divided into two streams: approximately $20 \%$ went to the detector while the major part was guided out of the oven through a $30 \mathrm{~cm} \times 1 / 16$ " teflon 
tubing, inserted in an electrically heated $\left(200^{\circ} \mathrm{C}\right)$ copper tube. Fractions were collected in 20 $\mathrm{cm} \times 0.8 \mathrm{~mm}$ (i.d.) melting point capillaries connected to the outlet tube and cooled with dry ice. The material trapped in the glass tube was dissolved in $20 \mu \mathrm{l}$ of trichlorofluoromethane using a $50 \mu \mathrm{l}$ glass syringe with a $0.5 \mathrm{~mm}$ o.d. needle. The solvent forms a liquid plug in the tube making thorough washing easy. The solution was placed in a small glass vial and concentrated to a volume of 4-5 $\mu$, ready for splitless injection onto a capillary column. Using 3(methylthio)-1-propanol and 3-(methylthio)propyl acetate as test substances the recovery was found to be approximately $40 \%$. The oven temperature programme was: 60 to $180^{\circ} \mathrm{C}$ with a rate of $5 \% \mathrm{~min}$. The carrier gas was $\mathrm{He}$.

Capillary column GC was carried out on a Perkin-Elmer Sigma 1 instrument equipped with a flame ionization and a flame photometric detector (FPD), set to sulphur mode. The injection system was an SGE Unijector, operating in splitless mode. The columns used were a Quadrex fused silica, $50 \mathrm{~m} \times 0.32 \mathrm{~mm}$ (i.d.), type 007 methyl silicone, $1 \mu \mathrm{m}$ film thickness, a glass SGE SCOT, $58 \mathrm{~m} \times 0.48 \mathrm{~mm}$ (i.d.), type 50GS/ FFAP, and a Chrompack fused silica, $50 \mathrm{~m} \times 0.32$ mm (i.d.), type CP WAX $57 \mathrm{CB}, 1.2 \mu \mathrm{m}$ film thickness. A low dead volume effluent splitter, located in the column oven, allowed the simultaneous use of both detectors. The FPD/FID flow ratio was adjusted to $10: 1$. The most frequently used oven temperature programme was: 10 to $250^{\circ} \mathrm{C}$, rate $2 \%$ min to $60^{\circ} \mathrm{C}$ and $4^{\circ} / \mathrm{min}$ from $60^{\circ} \mathrm{C}$. The carrier gas was $\mathrm{He}$.

\subsection{Gas Chromatography-Mass Spectrometry} GC-MS was carried out on a VG 7070F instrument equipped with a VG 2035 Data System and a Pye Unicam Series 204 gas chromatograph. The instrument was set to electron impact mode. The columns used were the above mentioned Quadrex fused silica, methylsilicone capillary column or a $1.5 \mathrm{~m} \times 2 \mathrm{~mm}$ (i.d.) glass column packed with $5 \%$ OV-101 on Chromosorb W HP, 80/100 mesh. Carrier gas, He; ion source temp., $220^{\circ} \mathrm{C}$; ionization energy, $70 \mathrm{eV}$.

\subsection{NMR spectroscopy}

NMR spectra were recorded on Bruker WH90 and AM-500 instruments. Deuterochloroform $(76.9 \mathrm{ppm})$ was used as internal reference in the ${ }^{13} \mathrm{C}$ spectrum and TMS as internal standard for the ${ }^{1} \mathrm{H}$ spectra.

\subsection{Syntheses}

\subsubsection{Synthesis of (1-methylethyl)-thiirane}

(Scheme 1, no. 2)

A mixture of 3-methyl-2-buten-1-ol (Scheme 1, no. 1) (15.5 g), ethanethioic acid ( $34.4 \mathrm{~g})$, and dibenzoyl peroxide $(0.36 \mathrm{~g})$ was heated to $60^{\circ} \mathrm{C}$ for $2 \mathrm{~h}$ and then to $100^{\circ} \mathrm{C}$ for $1 \mathrm{~h}$. With stirring and cooling a solution of $\mathrm{KOH}(53 \mathrm{~g})$ in water $(125 \mathrm{ml})$ was added. The mixture was heated to $60^{\circ} \mathrm{C}$ for $5 \mathrm{~min}$, cooled in ice, and extracted with $50 \mathrm{ml}$ of trichlorofluoromethane. The organic phase was dried over $\mathrm{Na}_{2} \mathrm{SO}_{4}$. Distillation gave a main fraction of the title compound, b.p. 126-31 ${ }^{\circ} \mathrm{C}$. Redistillation afforded a sample, b.p. $121-22{ }^{\circ} \mathrm{C}\left[116^{\circ}(3)\right]$ that was homogeneous according to GC. ${ }^{1} \mathrm{H}$ NMR, $500 \mathrm{MHz}, \mathrm{CDCl}_{3}$ soln., coupling constants $(\mathrm{J})$ in $\mathrm{Hz}: \delta 1.09(\mathrm{~d}, \mathrm{~J}$ $\left.=6.9, \mathrm{CH}_{3}\right) ; 1.11\left(\mathrm{~d}, \mathrm{~J}=6.9, \mathrm{CH}_{3}\right) ; 2.2(\mathrm{dd}, \mathrm{J}=$ 6.0 and $0.9, \mathrm{H}(3)$ cis to the isopropyl group); 2.5 (dd, $\mathbf{J}=6.6$ and $0.9, \mathrm{H}(3)$ trans to the isopropyl group); 2.7 (ddd, $J=6.6,6.0$ and 6.0, $\mathrm{H}(2)$ ). The $\mathrm{H}(3)$ signals were assigned with the aid of a nuclear Overhauser experiment (n.O.e.). ${ }^{13} \mathrm{C}$ NMR, $90 \mathrm{MHz}, \mathrm{CDCl}_{3}$ soln., C-H coupling constants $(\mathbf{J})$ in $\mathrm{Hz}: \delta 21.3\left(\mathrm{~J}=127.0, \mathrm{CH}_{3}\right) ; 21.5$ $\left(\mathbf{J}=127.0, \mathrm{CH}_{3}\right) ; 24.4(\mathrm{~J}=167.5, \mathrm{C} 3) ; 34.8(\mathrm{~J}$ $=131.5, \mathrm{C} 4) ; 42.8(\mathrm{~J}=166.5, \mathrm{C} 2)$.

\subsubsection{Synthesis of 2-mercapto-3-methyl-1- butanol (Scheme 2, no. 3)}

A solution of 3-methyl-2-buten-1-ol (Scheme 2 , no. 1) $(3.5 \mathrm{ml})$, in light petroleum $\left(40-60{ }^{\circ} \mathrm{C}\right)$ $(20 \mathrm{ml})$ was placed in a $100 \mathrm{ml}$ quartz flask. After lowering the temperature to $-50{ }^{\circ} \mathrm{C}$ with a $\mathrm{CO}_{2}$ /acetone bath a continuous stream of $\mathrm{H}_{2} \mathrm{~S}$ gas was led into the solution while the flask was being irradiated with a $50 \mathrm{~W}$ mercury UV-lamp for $20 \mathrm{~min}$. Distillation in vacuum gave a forerun of unreacted substrate and a main fraction of the title compound, $0.3 \mathrm{~g}$, b.p. $75-80$ ${ }^{\circ} \mathrm{C} / 13 \mathrm{~mm} \mathrm{Hg}$. Most of the product was a high 
boiling residue. GC analysis of the main fraction showed the presence of $7 \%$ of the substrate. Redistillation afforded a $97 \%$ pure sample. ' $\mathrm{H}$ NMR, $500 \mathrm{MHz}, \mathrm{CDCl}_{3}$ soln., coupling constants ( $\mathbf{J})$ in $\mathrm{Hz}$ : $\delta 0.99\left(\mathrm{~d}, \mathbf{J}=6.6, \mathrm{CH}_{3}\right) ; 1.01$ (d, $\left.\mathbf{J}=6.6, \mathrm{CH}_{3}\right) ; 1.2(\mathrm{~d}, \mathbf{J}=9.0, \mathrm{SH}) ; 2.0(\mathrm{~m}, \mathrm{H}(3))$; 2.1 (broad s, OH); $2.8(\mathrm{~m}, \mathrm{H}(2)) ; 3.5(\mathrm{dd}, \mathrm{J}=8.3$ and $11.1, \mathrm{H}(1)) ; 3.8(\mathrm{dd}, \mathrm{J}=4.8$ and $11.1, \mathrm{H}(1))$.

\subsection{Sensory Evaluation}

\subsubsection{Preparation of samples}

Samples of bottled beer were taken from the production line of the breweries. The bottles were opened and gently fobbed to create a steady foam cap. The components to be tested, dissolved in degassed ethanol, were added beneath the foam layer by means of micro pipettes in amounts providing concentrations as listed in Table II. After addition the bottles were immediately recrowned.

\subsubsection{Evaluation}

Sensory evaluations were performed by a panel of 8 highly skilled assessors. They were asked to give a written description of the flavours of the samples and further to express an overall quality judgement on an arbitrary scale from 9 to 0 . At the end of the sessions the various descriptions were discussed.

\section{RESULTS AND DISCUSSION}

As mentioned in the introduction the onionlike off-flavour very likely was caused by one or more sulphur-containing volatiles. We therefore planned to analyse an extract of the off-flavour beer with gas chromatography using a sulphur sensitive flame photometric detector (FPD), and also to try to detect onion smelling components in the GC eluate organoleptically (by sniffing). Subsequent analysis with gas chromatographymass spectrometry would then, we hoped, allow identification of specific compounds.

As extraction solvent was chosen trichlorofluoromethane that has proved well suited for extraction of alcoholic beverages (5). Its main advantage is the high efficiency of extraction of most volatiles except for lower alcohols and water. High contents of ethanol and water in the extract would severely limit the attainable extent of concentration of volatiles in the extract. When dealing with trace components, as in the present work, a concentration step of 100 -fold or more will be necessary. In connection with this the low boiling point $\left(24^{\circ} \mathrm{C}\right)$ of trichlorofluoromethane is a further advantage. It also deserves mentioning that the cheap, industrial solvent only contains minute amounts of impurities giving signals in the GC sulphur trace.

A GC analysis of a concentrated extract obtained from extraction of $330 \mathrm{ml}$ of off-flavour beer with $50 \mathrm{ml}$ of trichlorofluoromethane, using a polar (Carbowax 20M) packed column, gave an encouraging result: a strong, onion-like smell appeared in the eluate at a distinct time, between the elution times of two of the major sulphur-containing volatiles of beer, 3(methylthio)-propyl acetate and 3-(methylthio)1-propanol, eluting in that order. Unfortunately, GC-MS analysis, still using a packed column, revealed that the $\mathrm{GC}$ region of interest was very intense, complex and poorly resolved, and mass spectra suggesting the presence of sulphur compounds were not obtained. In order to obtain better GC resolution a capillary column was then employed. Even though a column with relatively large diameter and film thickness was selected (Quadrex type 007 methyl silicone), a much smaller sample load, compared to that on the packed column, had to be used. In return, there was a high gain in signal amplitudes due to much narrower bands. With splitless, solvent effect technique we found it possible, in the sense of obtaining fairly well resolved and reproducible chromatograms, to inject the total amount of concentrated extractives from extraction of $280 \mathrm{ml}$ of beer with $2 \mathrm{ml}$ of trichlorofluoromethane. Injection of larger amounts resulted in chromatograms with several major constituents giving split peaks. Figure 1A shows FID and FPD traces of an extract of beer of usual quality, Carlsberg lager. A number of the sulphur-containing components (upper trace) were identified by GC-MS. Single-ion monitoring at $\mathrm{m} / \mathrm{z} 47\left(\mathrm{CH}_{3} \mathrm{~S}\right)$ was useful for tracing most of the compounds. In most cases the mass spectra obtained were weak and/or impure owing to small amounts of sulphur compounds and a 

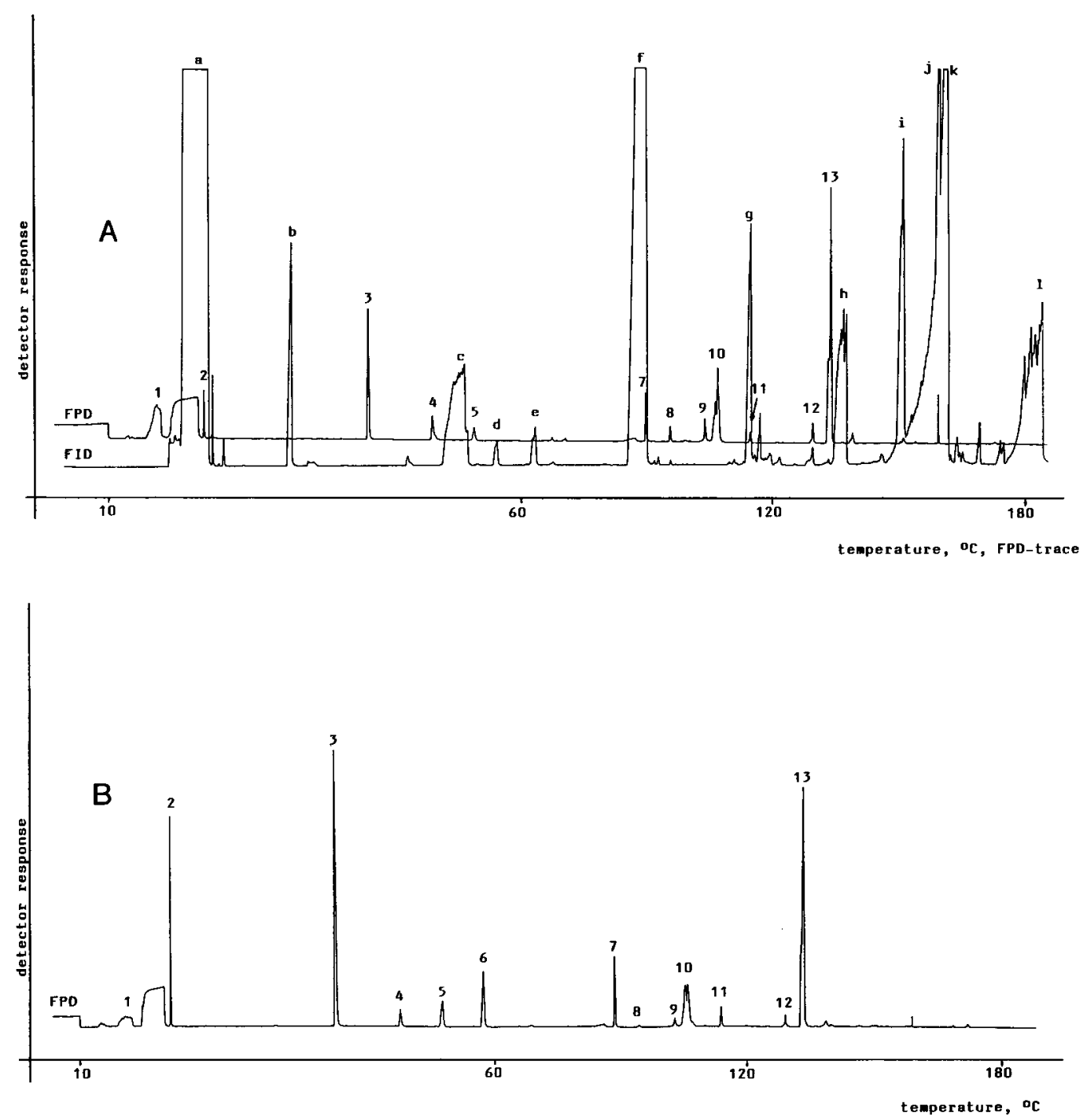

Figure 1. A) Capillary column gas chromatograms of an extract of Carlsberg lager beer. Upper trace: sulphur sensitive flame photometric detector (FPD) signal; lover trace: flame ionization detector (FID) signal. The traces are horizontally offset as indicated by the starting points. The sulphur peaks in Figures 1A and 1B, Nos. 1-13, are commented on in Table I. Major non-sulphur components are: a, solvent; b, ethyl acetate; $c$, pentanols; $d$, 2-methylpropyl acetate; e, ethyl butanoate; f, 3-methylbutyl acetate; g, ethyl hexanoate; h, 2-phenylethanol; i, ethyl octanoate; $j$, octanoic acid; $k$, 2-phenylethyl acetate; and 1 , decanoic acid.

B) GC trace of sulphur-containing constituents of an extract of beer with onion-like off-flavour. To be compared with the trace of sulphur compounds in Figure 1A. See Table I.

heavy load of non-sulphur peaks, at a much higher concentration level. The FID trace shown is deceiving in this respect because of the low FID/FPD split ratio and a high FID amplifier damping. The retention times of the sulphur peaks were checked with authentic reference compounds. In order also to make quantitative analyses, known amounts of these, dissolved in ethanol, were added to the beer prior to extraction. Results and literature data are given in Table I. Major non-sulphur components are listed in the legend to Figure 1A. 
Table I. Identities and quantities of sulphur constituents in beer represented by peaks Nos. 1-13 in Figure $1 \mathrm{~A}$ (upper trace) and Figure 1B.

\begin{tabular}{|c|c|c|c|c|}
\hline Peak No. & Identity & $\begin{array}{l}\text { Conc. } \\
\text { (ppb) }\end{array}$ & $\begin{array}{l}\text { Conc. values } \\
\text { (ppb) } \\
\left.\text { from literature }{ }^{a}\right)\end{array}$ & $\begin{array}{l}\text { Flavour } \\
\text { thresholds } \\
\text { (ppb) }\end{array}$ \\
\hline 1. & methanethiol & n.d. & $0-1$ & $0.15-30^{\mathrm{a}}$ \\
\hline 2. & dimethyl sulphide & 7 & $10-200$ & $33^{a}$ \\
\hline 3. & ethanethioic acid S-methyl ester & 4 & $10-28$ & n.d. \\
\hline 4. & dimethyl disulphide & 0.4 & $1-3$ & $7^{\mathrm{a}}$ \\
\hline 5. & ethanethioic acid S-ethyl ester & 1 & $1-3$ & n.d. \\
\hline 6. & (1-methylethyl)-thiirane & 1.5 & n.d. & $<10^{\mathrm{b}}$ \\
\hline 7. & $\begin{array}{l}\text { 3-(methylthio)-propanal (?) } \\
\text { (methional) }\end{array}$ & n.d. & $<50$ & $4-250^{a}$ \\
\hline 8. & unknown ${ }^{\mathrm{c}}$ & & & \\
\hline 9. & methyl 3-(methylthio)-propanoate (?) ${ }^{\mathrm{c}, \mathrm{d}}$ & n.d. & n.d. & n.d. \\
\hline \multirow[t]{2}{*}{10.} & dimethyl trisulphide and & 0.02 & n.d. & $<0.03^{b}$ \\
\hline & $\begin{array}{l}\text { 3-(methylthio)-1-propanol } \\
\text { (methionol) }\end{array}$ & n.d. & $50-1300$ & $2000^{\circ}$ \\
\hline \multirow[t]{2}{*}{11.} & 2-acetyl-thiophene and & n.d. & n.d. & n.d. \\
\hline & 2-mercapto-3-methyl-1-butanol ${ }^{\mathrm{e}}$ & 7 & n.d. & $<1^{b}$ \\
\hline 12. & ethyl 3-(methylthio)-propanoate & 0.4 & n.d. & n.d. \\
\hline 13. & $\begin{array}{l}\text { 3-(methylthio)-propyl acetate } \\
\text { (methionyl acetate) }\end{array}$ & 9 & $13-30$ & $600^{2}$ \\
\hline
\end{tabular}

a. data from ref $(10) ;{ }^{b}$. approximative determination at the Carlsberg Research Center; ${ }^{c}$. no mass spectrum obtained; ${ }^{d}$. not previously reported as a beer flavour constituent, but known from wine, ${ }_{j}^{e}$, the assignment of peak no. 11 to these constituents is tentative, based on retention time considerations and the fact that the peak is reproducibly higher in chromatograms of off-flavour beer than in those of standard beer. The two, nearly coeluting compounds were identified by GC-MS analysis of another extraction, see text. n.d. = not determined.

Figure 1B shows the GC sulphur trace obtained from beer with onion-like off-flavour. The only, but noticeable, qualitative difference from the sulphur trace in Figure $1 \mathrm{~A}$ is the appearance of a new peak, no. 6. With GC-MS, again using $\mathrm{m} / \mathrm{z} 47$ single-ion monitoring for tracing sulphur compounds, a mass spectrum of the new compound was recorded. After correction for background signals, mainly due to a tail of pentanols, the partial spectrum shown in Figure 2 emerged. The assumed molecular ion peak at $\mathrm{m} / \mathrm{z} 102$ showed a $4-5 \% \mathrm{M}+2$ isotope peak, confirming that the spectrum was actually derived from a sulphur compound. With the aid of peak matching technique on the mass spectrometer the elemental composition was established to be $\mathrm{C}_{5} \mathrm{H}_{10} \mathrm{~S}$, corresponding to unsaturated or cyclic thiols and sulphides, and thiocarbonyl compounds. We soon realized, however,

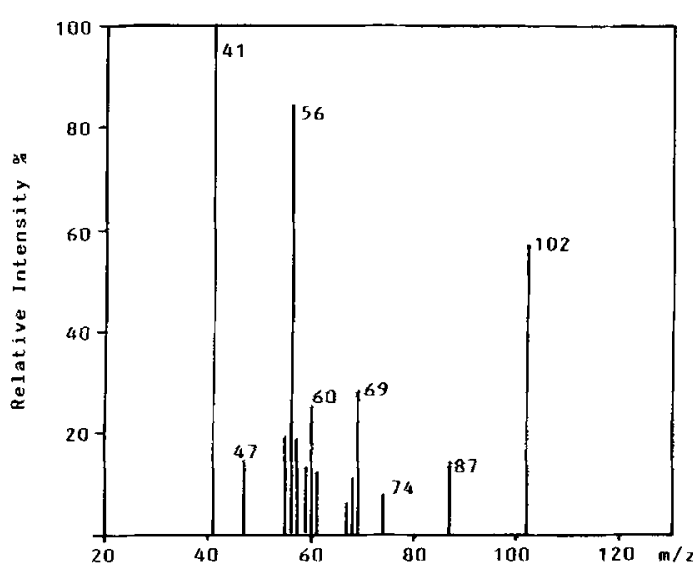

Figure 2. Mass spectrum of sulphur-containing component corresponding to peak no. 6 in Figure 1B. 
and later proved that the compound could not be the onion-smelling constituent detected in the eluate from the polar, packed column, because no compound belonging to the above mentioned categories is sufficiently polar to elute close to (3-methylthio)-1-propanol on a polar column, as in fact observed for the onionsmelling constituent. But since the compound, being present in off-flavour beer only, must in some way be related to or even contributing to the off-flavour, we decided to try to determine its structure. The composition $\mathrm{C}_{5} \mathrm{H}_{10} \mathrm{~S}$ comprises 78 structural isomers, not counting tautomers of thiocarbonyl compounds. Assuming the unknown compound to be of natural origin we decided to consider isoprenoid structures only, and to exclude, at first, cyclopropane and cyclobutane derivatives. That reduced the list to 17 compounds: 7 thiols, 3 thietanes, 3-methyl-tetrahydrothiophene, 3 thiocarbonyl compounds and 3 thiiranes.

The strategy for the identification was to compare mass spectra from the literature or from our own instrument with that of the unknown (Figure 2), and to test GC retention times on one or, in case of a positive result, two columns with different retention characteristics. Since it is known that mass spectral intensity patterns vary with instrumental parameters, and that isomers may exhibit very similar mass spectra, structures were rejected on the basis of literature data only when these were markedly different from our spectrum. In other cases the compounds were synthesized. The syntheses were carried out on a small scale using standard methods. Of the 7 thiols, 6 of which were synthesized, 3-methyl-3-buten-1-thiol showed a good mass spectral fit but did not match with the GC retention time on one of the two columns. The same applied to 2,2-dimethylthietane. After having ruled out thiocarbonyl compounds (only 3-methyl-2-butanethione was prepared) and 3-methyl-tetrahydrothiophene (synthesized) we were left with 3 thiiranes. At the same time we were re-examining a GC-MS analysis of a complex mixture from an attempted synthesis of unsaturated thiols by acid catalysed reaction of 3-methyl-2-buten-1-ol with ethanethioic acid followed by treatment with aqueous $\mathrm{KOH}$. In the collection of mass spectra from the analysis,

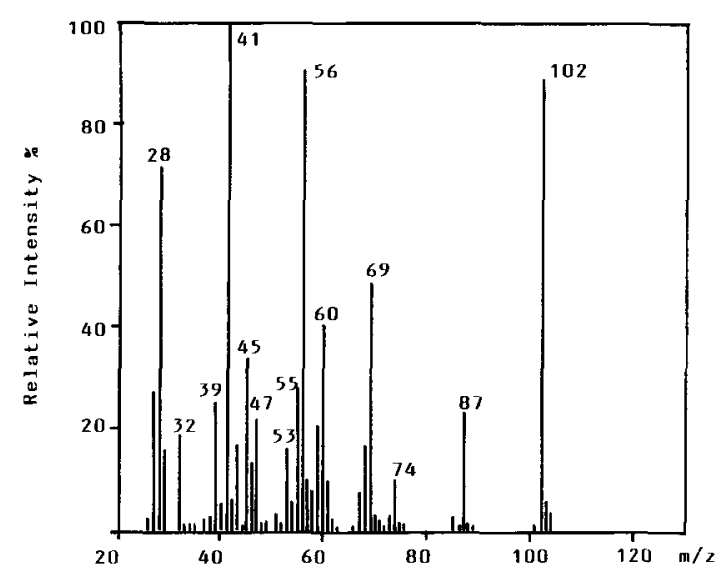

Figure 3. Mass spectrum of authentic (1-methylethyl)thiirane.

one resembled that of the unknown (Figure 2), though impure and weak (recorded on the tailing edge of another component). Since the only thiol that would fit mass spectrometrically, viz. 3-methyl-3-buten-1-thiol, was not likely to result from the reaction sequence, it was presumed that the spectrum was actually due to a thiirane, namely the (1-methylethyl)-derivative, arising in trace amounts via the steps in Scheme 1. By using dibenzoyl peroxide to induce radical addition of ethanethioic acid across the C-C double bond a high yield of (1-methylethyl)-thiirane was obtained. The mass spectrum of this compound (Figure 3) is seen to match the partial spectrum of the unknown well. GC retention times of the thiirane and the unknown were identical on two columns. Hence, it was concluded that the $\mathrm{C}_{5} \mathrm{H}_{10} \mathrm{~S}$ component in off-flavour beer was (1-methylethyl)-thiirane. This compound has been described in the literature as a synthetic substance only, in connection with polymerization studies. The synthesis followed a four-step route starting from 3-methyl-2-butanone (3).
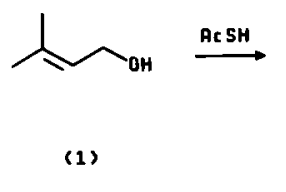<smiles>CCCCC(CC(C)C)C(C)C</smiles>
$\stackrel{\mathrm{OH}^{-} / \mathrm{H}^{2} \mathrm{O}}{\longrightarrow}$<smiles>CC(C)C1CS1</smiles>

(2)

Scheme 1 
Table II. Flavour effect of the two sulphur components added to beer

\begin{tabular}{lllcll}
\hline & (1-Methylethyl)-thiirane & & & \multicolumn{2}{l}{ 2-Mercapto-3-methyl-1-butanol } \\
\hline ppb & Description & Score & ppb & Description & Score \\
\hline 0 & Normal & 7.7 & 0 & Normal & 7.8 \\
4.6 & Very slight deviation & 7.3 & 0.1 & Slight, unspecific deviation & 7.2 \\
9.3 & Slight onion/garlic & 6.3 & 1 & Slight onion & 5.8 \\
18.5 & Noticeable onion/garlic $^{\mathrm{a}}$ & 4.5 & 5 & Noticeable onion $^{\mathrm{b}}$ & 4.7 \\
37.1 & Marked onion/garlic $^{\mathrm{a}}$ & 2.3 & 10 & Marked onion $^{\mathrm{b}}$ & 3.8 \\
74.2 & Very strong onion/garlic $^{\mathrm{a}}$ & 0.3 & 20 & Very strong onion $^{\mathrm{b}}$ & 1.8 \\
\hline
\end{tabular}

a. The flavour note is found different from the authentic onion flavour.

b. The flavour note is found identical with the authentic onion flavour.

As anticipated, the thiirane was not a major onion-like off-flavour constituent. Results of taste testing panel experiments are shown in Table II. The flavour produced by adding the thiirane to beer, though onion/garlic-like, was different from the authentic off-flavour. Furthermore, the flavour threshold value of the compound was higher than its concentration in beer (Table I). Since the GC sulphur trace of the off-flavour beer extract apparently did not show other abnormal components than the thiirane, we concluded that the onion-smelling constituent was too polar and/or present in too low concentration to be extracted, with the smallvolume single-step procedure, in an amount sufficient for detection. See, however, comments related to peak no. 11 in Table I.

A more efficient, continuous extraction was then carried out. In order to use the capillary column for GC analysis, a fraction of the extract containing the onion off-flavour was isolated by preparative GC, using the polar packed column and tracing the onion-smelling constituent organoleptically. Though narrowly cut the fraction contained considerable amounts of nonsulphurous material. The FPD detector gave two, partly overlapping sulphur peaks, fortunately lying in a "clean" region of the chromatogram. GC-MS analysis gave partially mixed mass spectra consistent with the presence of two sulphur components. One, showing intense peaks at $\mathrm{m} / \mathrm{z} 126$ and 111 , was identified as 2-acetyl-thiophene, a known beer flavour constituent (10). The other, suspected to be the onion-smelling constituent, showed a presumed molecular ion peak at $\mathrm{m} / \mathrm{z} 120$ and highest mass fragment peaks at $\mathrm{m} / \mathrm{z} 102$ and 89 , probably corresponding to losses of a molecule of water and a hydroxymethyl radical, respectively, from the molecular ion. The obvious structure, related to (1-methylethyl)-thiirane, was 2-mercapto3-methyl-1-butanol. The compound was easily synthesized by addition of $\mathrm{H}_{2} \mathrm{~S}$ to 3-methyl-2buten-1-ol, Scheme 2.

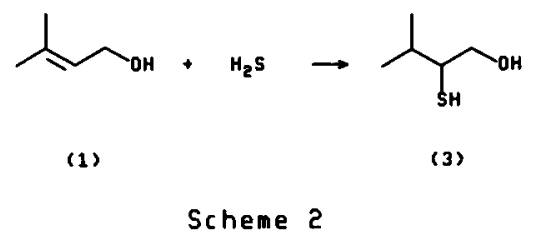

Its mass spectral (Figure 4) and GC retention time characteristics matched with those of the beer constituent. It possesses a strong, onion-like smell at high dilution in air, and addition of an appropriate amount to beer of usual quality produced an off-flavour indistinguishable from the authentic (Table II). Therefore, the "onion principle" of the off-flavour beer undoubtedly is 2-mercapto-3-methyl-1-butanol. The compound has not been described in the available literature (no records in Chemical Abstracts and Beilstein).

No attempts were made to determine the enantiomeric composition of the sulphur compounds discussed above. At present their origin is not obvious. It is tempting, however, to speculate that they derive from certain isoprenoid structures, known to participate also in the formation of "light-struck" flavour after being 




Figure 4. Mass spectrum of authentic 2-mercapto-3methyl-1-butanol.

split off from hop iso- $\alpha$-acids (8). As mentioned above the onion flavour component may be synthesized from 3-methyl-2-buten-1-ol. Further, we have found that addition to wort of this alcohol may result in beer with an onion smell (12). It has been reported that 3-methyl-2-buten1 -ol as well as the isomeric 2-methyl-3-buten-2ol may be formed during wort-boiling as a result of degradation of the hop $\beta$-acid colupulone (14). We have been able to detect these two unsaturated alcohols in samples of normal wort (12). Preliminary pilot scale experiments have shown that the onion-like off-flavour is not found in beers produced without hops (12). Hence, the use of hops seems to be a necessary, but not sufficient, condition for the formation of the onion smell. Other factors, so far unknown, seem to be implied.

\section{ACKNOWLEDGEMENTS}

The assistance of KIRSTEN THORNBERG in describing the smell of the GC-effluents in the sniffing sessions is gratefully acknowledged. ULLA MAXMILLING is thanked for the assistance in synthesizing various reference compounds. Dr. BO JENSEN for inking in the chromatogram traces, and Drs. Mikael Begtrup and Klaus BOCK for kindly recording the NMR spectra. The valuable advice of Professor ANDERS KJÆR during this work and his help with the manuscript is appreciated.

\section{REFERENCES}

1. Ahvenainen, J., H. Vehviläinen \& V. Mäkinen: Einfluss der Trubentfernung auf die Gärung und Bierqualität. Brauwiss. 32, 141-144 (1979)

2. BäRwALD, G.: Die Schwefelverbindungen im Brauprozess. Der Brauereitechniker 23, 130-134 (1971)

3. Dumas, P., N. Spassky \& P.Sigwalt: Préparation et polymérisation de l'isopropylthiiranne racémique. C.R. Acad. Sc. Paris 277, 939-940 (1973)

4. Gunst, F. \& M. Verzele: On the sunstruck flavour of beer. J. Inst. Brew. 84, 291-292 (1978)

5. HARDY, P.J.: Extraction and concentration of volatiles from dilute aqueous and aqueous-alcoholic solution using trichlorofluoromethane. J. Agr. Food Chem. 17, 656-658 (1969)

6. Hough, J.S., D.E. Briggs, R. Stevens \& T.W. YouNG: Malting and brewing science, volume 2. Hopped wort and beer, second edition, Chapman and Hall, London, New York, 481 (1982)

7. Jounela-ERIKSSON, P., A. LINDEMAN \& V. ARKIMA: Individual variation in perceiving flavours and its effect on the acceptance of beer samples. Proceedings of the European Brewery Convention Congress, Helsinki, 707-714 (1985)

8. Kuroiwa, Y., N. Hashimoto, H. Hashimoto, E. KoKUbO \& K. NAKAGANA: Factors essential for the evolution of sunstruck flavour. Proc. Am. Soc. Brew. Chem. 181-193 (1963)

9. LIEBENOW, R. \& K.D. ESSER: Erfahrungen mit der Heissbelüftung der Ausschlagwürze. Mschr. Brauerei 20, 23-24 (1967)

10. Meilgaard, M.C.: Beer Flavour. Thesis, the Technical University of Denmark (1981) University Microfilms International, Ann Arbor, Michigan, USA

11. Narziss, L. \& L. Meyer: Die Auswirkung der Heisstrubabscheidung bei Whirlpools und Zentrifugen. Brauwelt 33, 1191-1200 (1978)

12. OLSEN, A.: Unpublished results

13. PePpard, T.L.: Dimethyl trisulphide, its mechanism of formation in hop oil and effect on beer flavour. J. Inst. Brew. 84, 337-340 (1978)

14. REgAN, J.P. \& J.A. Elvidge: Chemistry of hop constituents. Part XXXIII. Reactions of $\beta$-acids. J. Inst. Brew. 75, 10-14 (1969)

15. Seaton, J.C., A. Suggett \& M. Moir: The role of sulphur compounds in beer flavour. European Brewery Convention Monograph VII, Copenhagen, 143-155 (1981)

Accepted by H. KLENOw 